\title{
Изучение конкурентной адсорбции модификаторов на частицах полимерцементной системы для аддитивных технологий
}

\author{
Полуэктова В.А., Шаповалов Н.А., Кожанова Е.П. \\ ФГБОУ ВО «Белгородский государственный технологический университет им. В.Г. Шухова», \\ Белгород
}

Поступила в редакцию 23.08.2018 г.

DOI: https://doi.org/10.17308/sorpchrom.2019.19/748

\begin{abstract}
Приведены результаты исследований адсорбции олигомерных молекул флороглюцинфурфурольного модификатора на частицах поликомпонентных дисперсий. Изучен процесс десорбции молекул поливинилового спирта с поверхности частиц поливинилацетата при создании полимерцементной системы для аддитивных технологий в результате разбавления поливинилацетатной дисперсии водой затворения, при добавлении высокодисперсного минерального порошка (цемента) и в результате конкурентной адсорбции флороглюцинфурфурольных олигомеров с полимерными молекулами поливинилового спирта. Доказано, что флороглюцинфурфурольные олигомеры обладают бо́льшей поверхностной активностью на границе «поливинилацетат - дисперсионная среда полимерцементной системы», чем полимерные молекулы поливинилового спирта.
\end{abstract}

Ключевые слова: адсорбция, десорбция, поливиниловый спирт, флороглюцинфурфурольные олигомеры, полимерцементные системы, строительная 3D-печать.

\section{The research of modifiers competitive adsorption on polymer-cement system particles for additive technolodies}

\author{
Poluektova V.A., Shapovalov N.A., Kozhanova E.P. \\ «Belgorod State Technological University named after V.G. Shukhov», Belgorod
}

\begin{abstract}
Polymer and mineral dispersions have highly-developed surface possessing surface energy excess; consequently, coagulation processes may take place during polymer-mineral system making. Aggregate stable modified polyvinyl-acetate cement systems for additive technologies mean simultaneous presence of more than one surface-active material - phloroglucinefurfurol oligomers and polyvinyl alcohol. Polyvinyl alcohol is added into the system at the stage of vinyl acetate polymerisation as the stabilizer of the polymer dispersion. The phloroglucinefurfurol plasticizer provides the system rheology demanded by innovative technologies. The research of competitive adsorption of surface-active materials is of great interest. The authors of the work have used the method of ultraviolet spectroscopy to get adsorption isotherms of oligomer molecules of phloroglucinefurfurol superplasticizer on particles of multicomponent dispersions. The refractometric analysis with the help of additives has made it possible to study the desorption process of polyvinyl alcohol molecules from the surface of polyvinyl acetate particles during polymer-cement system making. The process of desorption takes place as a result of dispersion dilution with hardening water, while adding highlydispersive mineral powder (cement) and as a result of competitive adsorption of phloroglucinefurfurol oligomers. The up-to-date instrument for determining the contact angle, KRUSS Easy Drop DSA-30 (Germany), has been used to research colloid-chemical characteristics of mineral and polymer surfaces in conjunction with dispersion medium, containing surface-active materials under study. The works demonstrates de-
\end{abstract}


pendences of surface tension and contact angles on polyvinyl alcohol concentration and phloroglucinefurfurol superplasticizer. It has been proved that phloroglucinefurfurol oligomers possess bigger surface activity on the boundary «polyvinyl acetate - dispersion medium of polymer-cement system» than polymer molecules of polyvinyl alcohol. The colloid-chemical properties and interaction patterns of explored surfaceactive materials on the phase boundary of multicomponent dispersions have significant importance not only for colloid chemistry but for modern innovative science and engineering as well.

Keywords: adsorption, desorption, polyvinyl alcohol, phloroglucinefurfurol oligomers, polymercement systems, construction 3D printing.

\section{Введение}

Стремительное развитие трехмерной печати строительных объектов с помощью аддитивных технологий требует уникальных по реотехнологическим свойствам материалов [1-3]. Состав должен быть тиксотропным, то есть уменьшать вязкость при механическом воздействии, а в состоянии покоя - увеличивать $[1,4]$. При этом материал должен обладать хорошей пластической прочностью, то есть предел текучести дисперсии должен быть достаточным, чтобы выдержать нагрузку последующих слоев, и высокой адгезионной прочностью между слоями. Получение материала с требуемыми свойствами возможно с одной стороны путем создания композиционного материала на основе двух дисперсий: минеральной и полимерной, а с другой стороны путем модифицирования поверхности частиц дисперсий суперпластификаторами [5]. Основу полимерцементных систем составляет высококонцентрированная минеральная дисперсия допустимое содержание полимерной дисперсии до 20-25\% от массы цемента [6]. И полимерные добавки, и химические модификаторы поверхности раздела фаз в значительной степени влияют на коллоидно-химические, физико-механические и другие свойства минеральных систем и готовых изделий. Изучение процессов адсорбции молекул суперпластификаторов на поверхности твердых частиц полимерцементных дисперсий позволит целенаправленно управлять реологическими свойствами смесей. В связи с этим исследование процессов, протекающих на границе раздела фаз в поликомпонентных дисперсных системах, является одной из важнейших задач не только коллоидной химии, но и современной науки и техники [7-9] .

Полимерные и минеральные дисперсии имеют высокоразвитую поверхность, обладающую избытком поверхностной энергии, вследствие чего при создании полимерминеральных систем возможны процессы коагуляции. Одной из причин коагуляции полимерных дисперсий является механические воздействия, например, интенсивное перемешивание. При механических воздействиях коагуляционные процессы протекают локально и сопровождаются появлением отдельных частиц коагулюма, а не одновременной коагуляцией всей дисперсии. Это наблюдалось в исследованиях при получении полимерцементных систем на основе поливинилацетатной дисперсии (ПВАД), стабилизированной поливиниловым спиртом (ПВС) [10].

В свете вышеизложенного, модифицированные полимерцементные системы для аддитивных технологий предполагают одновременное присутствие в системе более одного поверхностно-активного вещества (ПАВ) - флороглюцинфурфурольные олигомеры и поливиниловый спирт, поэтому изучение конкурентной адсорбции присутствующих ПАВ представляет большой интерес.

Целью данной работы было изучение конкурентной адсорбции флороглюцинфурфурольных олигомеров и полимерных молекул поливинилового спирта на частицах поливинилацетатцементной системы для аддитивных технологий, а также процесса десорбции молекул поливинилового спирта с поверхности частиц поливи-

Полуэктова и др. / Сорбционные и хроматографические процессы. 2019. Т. 19. № 3 
нилацетата в результате разбавления водой затворения или при добавлении высокодисперсного минерального порошка (цемента).

\section{Эксперимент}

Для достижения поставленной цели в качестве адсорбатов использовали:

1) суперпластификатор СБ-ФФ - синтезировали по методике, описанной в работе [11]. Химический состав СБ-ФФ представлен флороглюцинфурфурольными олигомерами, растворенными в воде (20\%-ый раствор). Строение элементарного звена олигомерной молекулы и 3D модель конформации молекулы, полученной с помощью молекулярного моделирования в программе SymApps, представлены на рис. 1.<smiles>Cc1cc([O-])c(C(C)C)c(O)c1O</smiles>

$a$

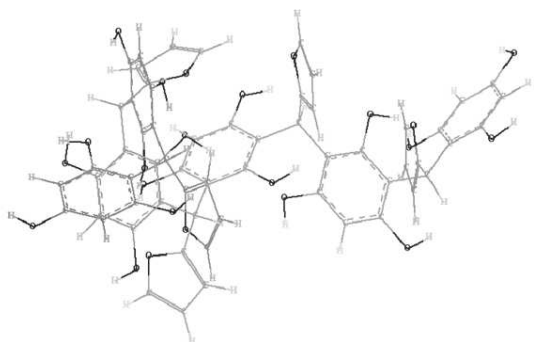

где $n=5 \div 6$.

Рис. 1. Строение элементарного звена и 3D модель конформации молекулы флороглюцинфурфурольного суперпластификатора

2) поливиниловый спирт (ГОСТ 10779-78) - готовили стандартный раствор с

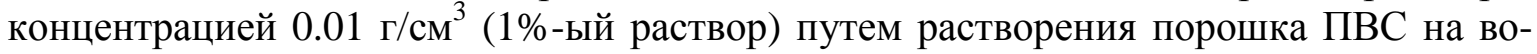
дяной бане. Все последующие концентрации получали методом разбавления.

Адсорбентами в полимерцементной системе при полимерцементном отношении (П/Ц) равном 0.1 выступали:

1) цемент - ПЦ-500-Д0-Н производства ЗАО «Осколцемент» с удельной поверхностью $2856 \mathrm{~cm}^{2} / \Gamma$. Минералогический состав: $\mathrm{C}_{3} \mathrm{~S}-60.19 \%, \mathrm{C}_{2} \mathrm{~S}-15.46 \%, \mathrm{C}_{3} \mathrm{~A}-$ $6.75 \%, \mathrm{C}_{4} \mathrm{AF}-14.74 \%$. Химический состав: $\mathrm{CaO}-65.77 \%, \mathrm{SiO}_{2}-21.23 \%, \mathrm{Al}_{2} \mathrm{O}_{3}-5.66 \%$, $\mathrm{Fe}_{2} \mathrm{O}_{3}-4.85 \%, \mathrm{MgO}-0.89 \%, \mathrm{SO}_{3}-0.45 \%$.

2) полимер - поливинилацетат в виде водной дисперсии (ПВАД) производства компании «Лакра», с содержанием дисперсной фазы не менее $51 \%$ со средним размером частиц 6.79 мкм. Частицы полимера стабилизированы поливиниловым спиртом (рис. 2), который введен в систему ещё на стадии полимеризации винилацетата в поливинилацетат.

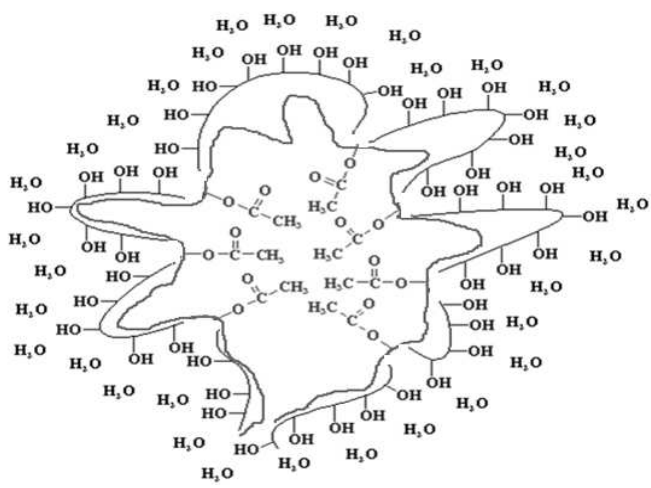

Рис. 2. Принцип действия ПВС в поливинилацетатной дисперсии 
Адсорбцию на частицах полимерцементных дисперсий изучали с помощью УФ-спектрометра (SPECORD UV) при волновом числе ультрафиолетовых лучей $v=50 \cdot 10^{3} \mathrm{~cm}^{-1}$ по убыли концентрации адсорбата в системе после установления адсорбционного равновесия спустя 20 минут. Перед спектрометрированием исследуемые системы центрифугировали 30 минут при 3000 об/мин. По результатам анализа строили изотермы сорбции.

Изучение процесса десорбции полимерных молекул ПВС проводили на рефрактометре ИРФ-22 с помощью рефрактометрического анализа методом добавок. Метод добавок позволял исключить влияние состава анализируемого раствора. Перед рефрактометрированием дисперсную фазу системы отделили центрифугированием и дополнительно отфильтровали. По результатам анализа строили график зависимости показателя преломления $n$ дисперсионной среды от концентрации добавки стандартного раствора ПВС $\left(C_{a}\right)$ (рис.3).

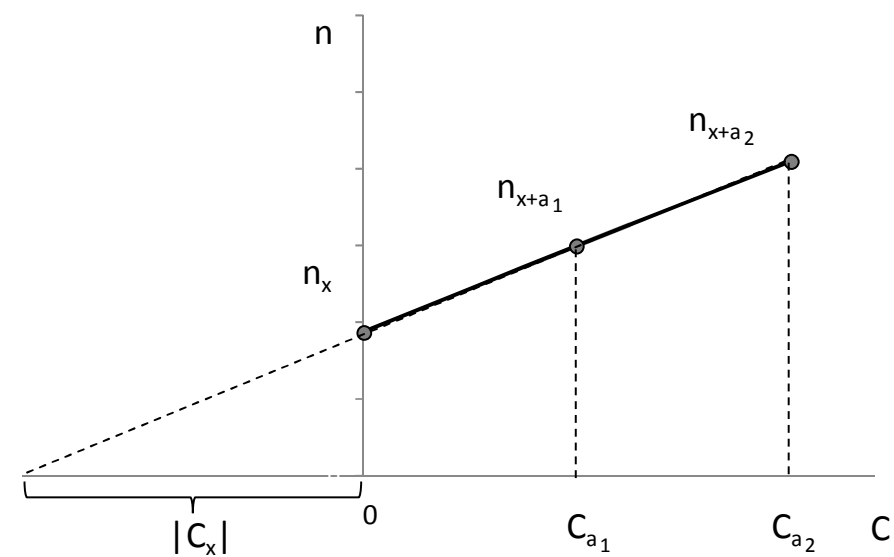

Рис. 3. Рефрактометрическое определение концентрации ПВС в дисперсионной среде системы методом добавок

По уравнению прямой находили концентрации при показателе преломления условно равном нулю и получали количество ПВС, десорбировавшегося с поливинилацетата (ПВА) в процессе разбавления дисперсии водой затворения, или при добавлении цемента (сохраняя полимерцементное отношение системы, равное 0.1), или в результате конкурентной адсорбции СБ-ФФ.

Измерение поверхностного натяжения растворов адсорбатов (СБ-ФФ и ПВС) с концентрациями $0.1 \% ; 0.05 \% ; 0.025 \% ; 0.0125 \% ; 0.0062 \% ; 0 \%$, краевых углов смачивания поверхности адсорбентов и свободной энергии поверхности проводили на прибор KRUSS Easy Drop DSA-30. В качестве минерального адсорбента использовали модельную систему по химическому составу - поверхность мрамора $\left(\mathrm{CaCO}_{3}\right)$. Для получения полимерной поверхности использовали ПВАД, нанесенный на предметное стекло и высушенный в естественных условиях.

Работу смачивания $\left(W_{\text {см }}\right)$ минеральной и полимерной поверхностей растворами ПАВ рассчитывали по формуле

$$
W_{\text {см }}=\sigma_{\text {ж-Г }} \cdot \cos \theta,
$$

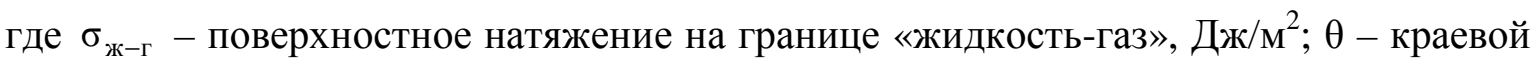
угол смачивания, град.

Влияние ПАВ на поверхностное натяжение на границе «твердое теложидкость» при образовании адсорбционного слоя молекул на поверхности минеральных и полимерных частиц оценивали классическим косвенным методом по изменению работы смачивания, используя формулу: 


$$
\sigma_{\text {т-ж }}=\sigma_{\text {т-Г }}-W_{\text {см }} .
$$

При $\sigma_{\text {т-г }}=$ const (по технике эксперимента) изменение работы смачивания принимали равным изменению поверхностного натяжения $\sigma_{\text {т-ж }}$, но с обратным знаком.

Поверхностное натяжение на границе «твердое тело-жидкость», называемое в настоящее время также свободной энергией поверхности (СЭП), для исследуемых поверхностей (минеральной и полимерной) было измерено непосредственно на приборе KRUSS Easy Drop DSA-30. Измерив краевые углы смачивания двух жидкостей с разной полярностью: дистиллированной воды (чистая полярность) и дийодометана (нет полярной составляющей), программное обеспечение ADVANCED прибора KRUSS Easy Drop DSA-30 рассчитало свободную энергию поверхности (СЭП) в мН/м, что эквивалентно мДж/м².

\section{Обсуждение результатов}

Исследование адсорбции молекул СБ-ФФ на полимерных и цементных частицах монодисперсий представлено в работе [12]. По полученным изотермам адсорбции сделаны выводы, что олигомерные молекулы модификатора СБ-ФФ адсорбируются как на минеральной, так и на полимерной поверхности дисперсных материалов.

В данной работе была рассмотрена адсорбция молекул СБ-ФФ на частицах полидисперсной системы при одновременном присутствии в системе полимерных и минеральных частиц (ПВА-цемент). Полученная изотерма адсорбции представлена на рис.4. Результат исследования сопоставим с ранее полученными данными, и позволяет сделать вывод о том, что адсорбция флороглюцинфурфурольного олигомера на поверхности полидисперсии (ПВА-цемент) выше, чем адсорбция в монодисперсиях на поверхностях частиц полимера и цемента. Емкость монослоя молекул СБФФ на поверхности полимера наименьшая, что говорит о наименьшей энергии взаимодействия «адсорбат-адсорбент», так как на поверхности полимера уже адсорбированы молекулы ПВС. Следовательно, на поверхности поливинилацетата наблюдается совместная адсорбция флороглюцинфурфурольных олигомеров с макромолекулами поливинилового спирта.

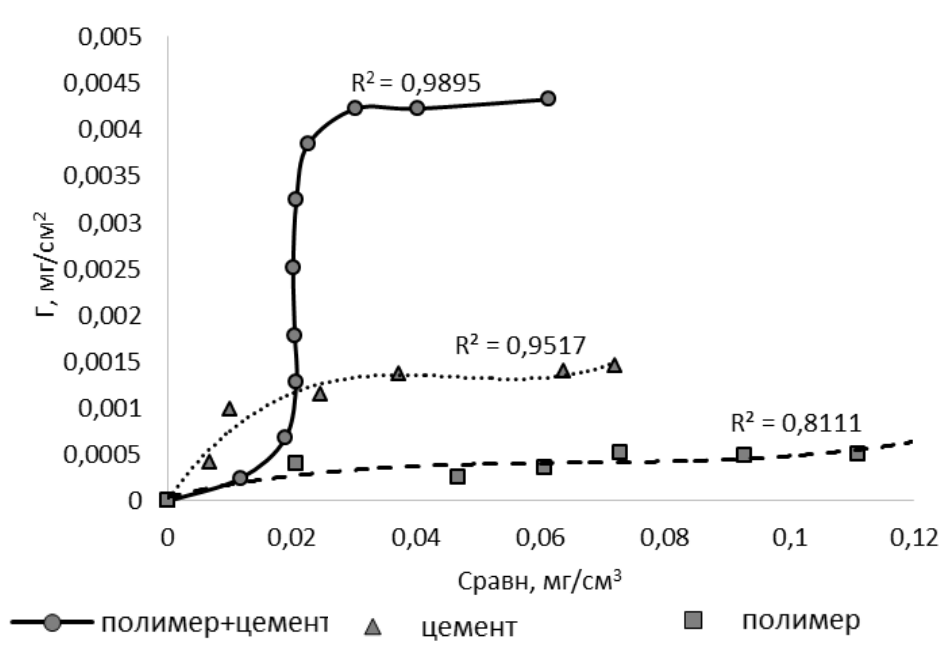

Рис. 4. Изотермы адсорбции олигомерных молекул флороглюцинфурфурольного модификатора на частицах в полимерцементной системе 
Изучение процесса десорбции молекул ПВС с поверхности частиц ПВА в результате разбавления ПВАД водой затворения, или при добавлении высокодисперсного минерального порошка (цемента), или в результате конкурентной адсорбции флороглюцинфурфурольных олигомеров проводили рефрактометрически методом добавок.

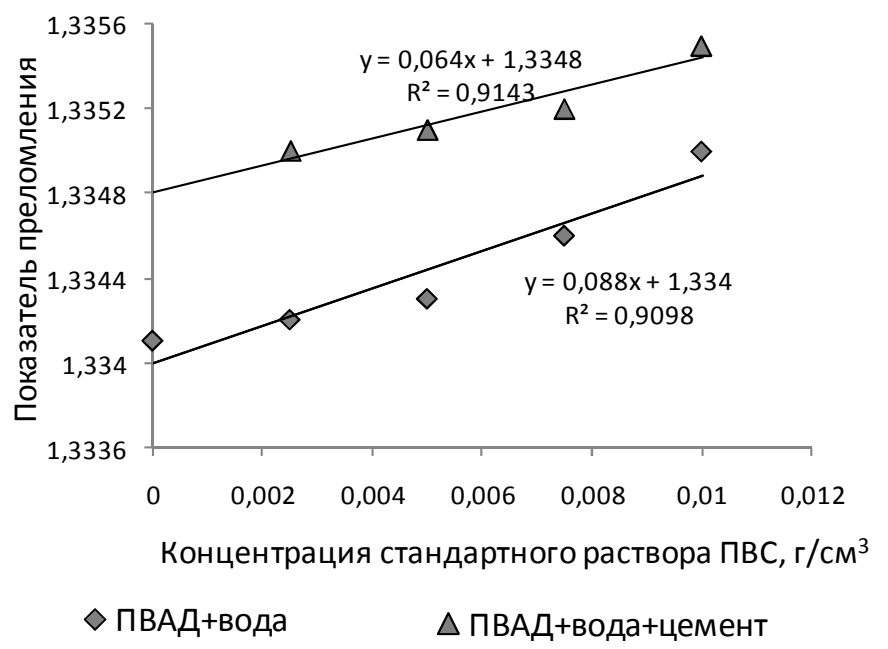

Рис. 5. Определение концентрации ПВС, десорбировавшегося при разбавлении ПВАД водой затворения и при добавлении порошкообразного материала с развитой поверхностью

По результатам рефрактометрического анализа построен график зависимости показателя преломления исследуемого раствора (дисперсионной среды после отделения центрифугированием дисперсной фазы) от концентрации добавки стандартного раствора ПВС (рис. 5). По уравнению прямых на графике

$$
\begin{gathered}
\mathrm{y}=0.088 \mathrm{x}+1.334 \text { (ПВАД+вода }) \\
\mathrm{y}=0.064 \mathrm{x}+1.3348(\text { ПВАД+вода+цемент) }
\end{gathered}
$$

находили концентрации ПВС при показателе преломления $n$ условно равном нулю $(\mathrm{y}=0)$, т.е. находили концентрацию ПВС в дисперсионной среде без концентрации добавки стандартного раствора ПВС и получали количество ПВС, десорбировавшегося с поливинилацетата.

По расчетам было установлено, что в присутствии цемента десорбируется на $38 \%$ ПВС больше, чем при разбавлении дисперсии водой, что и обуславливает коагуляцию полимерцементной системы.

При введении флороглюцинфурфурольных олигомеров в монополимерную дисперсию так же наблюдали увеличение десорбции молекул ПВС на 39\% с поверхности частиц ПВА, но при этом не наблюдалась коагуляция дисперсии, что объясняется конкурентной адсорбций СБ-ФФ на поверхности ПВА и выполнения им роли стабилизатора дисперсии. Данный вывод был подтвержден сравнением количества ПВС в дисперсионной среде полимерцементной системы без добавки и с СБ-ФФ. Результаты показали, что в присутствии флороглюцинфурфурольных олигомеров десорбируется на $23 \%$ больше ПВС, чем в немодифицированной полимерцементной системе.

Известно, что адсорбироваться должен преимущественно тот компонент, который обладает большей поверхностной активность на границе «твердое телораствор», т.е. сильнее снижает поверхностное натяжение на этой границе раздела фаз $\sigma_{\text {т-ж}}$. Для определения величины $\sigma_{\text {т-ж }}$ были измерены поверхностное натяжение на границе «жидкость-газ» $\sigma_{\text {ж-г }}$ растворов СБ-ФФ и ПВС методом висящей капли в воздухе (рис.6) и краевые углы смачивания $\theta$ минеральной $\left(\mathrm{CaCO}_{3}\right)$ и полимер- 
ной (ПВА) поверхностей растворами СБ-ФФ и ПВС (рис.7). По полученным результатам, используя формулу $W_{\text {см }}=\sigma_{\text {ж-г }} \cdot \cos \theta$, была рассчитана работа смачивания. Полученные и рассчитанные значения представлены в табл. 1.

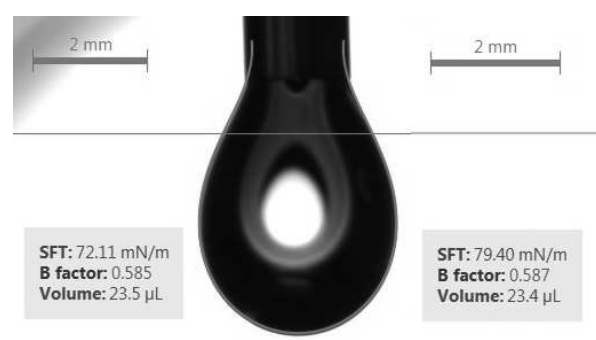

a

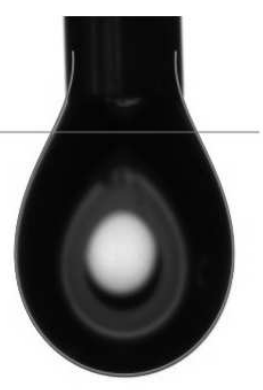

б

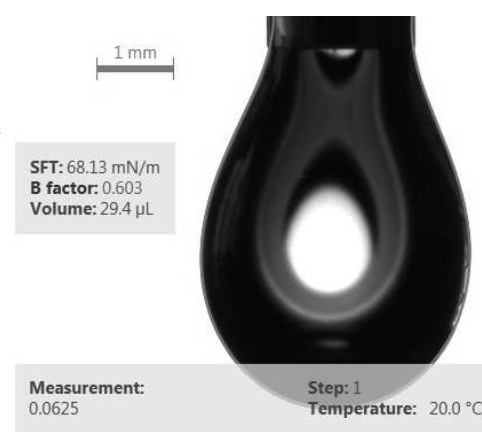

B

Рис.6. Поверхностное натяжение:

а - вода; б - 0.05\% раствора СБ-ФФ; в - 0.0625\% раствора ПВС

Таблица 1. Влияние поверхностно-активных веществ на коллоидно-химические параметры смачивания поверхности мрамора и поливинилацетата

\begin{tabular}{|c|c|c|c|c|c|c|c|}
\hline \multirow{2}{*}{\multicolumn{2}{|c|}{ Поверхность }} & \multicolumn{6}{|c|}{ Концентрация модификатора СБ-ФФ, \% } \\
\hline & & 0 & 0.0062 & 0.0125 & 0.025 & 0.05 & 0.1 \\
\hline \multicolumn{2}{|c|}{ 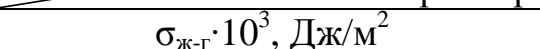 } & 72.1 & 81.3 & 76.7 & 81.4 & 79.4 & 78.8 \\
\hline \multirow{3}{*}{ Мрамора } & $\theta$, град & 77.5 & 75.8 & 74.2 & 73.5 & 70.9 & 69.7 \\
\hline & $\cos \theta$ & 0.22 & 0.25 & 0.27 & 0.28 & 0.33 & 0.35 \\
\hline & $\mathrm{W}_{\mathrm{cm}} \cdot 10^{3}$, Дж/ $\mathrm{M}^{2}$ & 15.9 & 20.3 & 20.7 & 22.8 & 26.2 & 27.6 \\
\hline \multirow{3}{*}{ Полимер } & $\theta$, град & 49.8 & 48.9 & 46.5 & 45.4 & 46.5 & 45.8 \\
\hline & $\cos \theta$ & 0.64 & 0.66 & 0.69 & 0.70 & 0.69 & 0.70 \\
\hline & $\mathrm{W}_{\mathrm{cm}} \cdot 10^{3}$, Дж/ $\mathrm{m}^{2}$ & 46.1 & 53.7 & 52.9 & 56.9 & 55.1 & 54.9 \\
\hline \multicolumn{2}{|c|}{ Поверхность } & \multicolumn{6}{|c|}{ Концентрация модификатора ПВС, \% } \\
\hline \multicolumn{2}{|c|}{ Параметр } & 0 & 0.0078 & 0.0156 & 0.0312 & 0.0625 & 0.125 \\
\hline \multicolumn{2}{|c|}{$\sigma_{\text {ж-г }} \cdot 10^{3}$, Дж/ $\mathrm{M}^{2}$} & 72.1 & 67.1 & 67.5 & 67.9 & 67.8 & 64.7 \\
\hline \multirow{3}{*}{ Мрамора } & $\theta$, град & 77.5 & 76.3 & 74.5 & 75.0 & 60.7 & 61.1 \\
\hline & $\cos \theta$ & 0.22 & 0.24 & 0.27 & 0.26 & 0.49 & 0.48 \\
\hline & $\mathrm{W}_{\mathrm{cm}} \cdot 10^{3}$, Дж/ $\mathrm{M}^{2}$ & 15.9 & 16.1 & 18.2 & 17.7 & 33.2 & 31.1 \\
\hline \multirow{3}{*}{ Полимер } & $\theta$, град & 49.8 & 49.6 & 48.5 & 47.8 & 42.7 & 42.0 \\
\hline & $\cos \theta$ & 0.64 & 0.65 & 0.66 & 0.67 & 0.74 & 0.74 \\
\hline & $\mathrm{W}_{\mathrm{cm}} \cdot 10^{3}$, Дж/ $\mathrm{m}^{2}$ & 46.1 & 43.6 & 44.6 & 45.5 & 50.2 & 47.9 \\
\hline
\end{tabular}

Результаты исследования влияния исследуемых ПАВ на коллоиднохимические параметры смачивания минеральной и полимерной поверхностей наглядно представлены в виде графической зависимости (рис. 8), показывающей влияние различных концентраций СБ-ФФ и ПВС на работу смачивания на поверхностях мрамора $\left(\mathrm{CaCO}_{3}\right)$ и полимера (ПВА). Так как поверхностное натяжение на границе «твердое тело-газ» является постоянным, то возрастание работы смачивания при введении ПАВ свидетельствует о понижении поверхностного натяжения на границе «твердое тело-жидкость». Из полученных данных можно сделать вывод, что СБ-ФФ обладает бо́льшей поверхностной активностью для полимера на границе «твердое тело-жидкость», чем ПВС. Подобная закономерность характерна и для минеральной поверхности, но только при малых концентрациях ПАВ. 
1. Краевой угол смачивания поверхности мрамора каплей

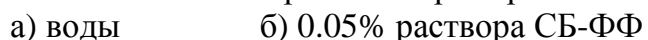

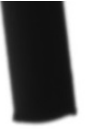

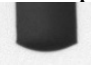

в) $0.0625 \%$ раствора ПВС
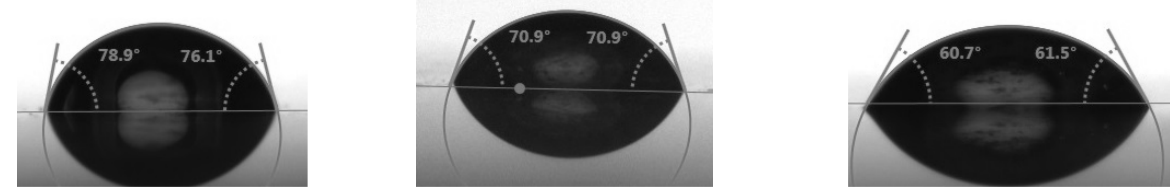

2. Краевой угол смачивания поверхности поливинилацетата каплей
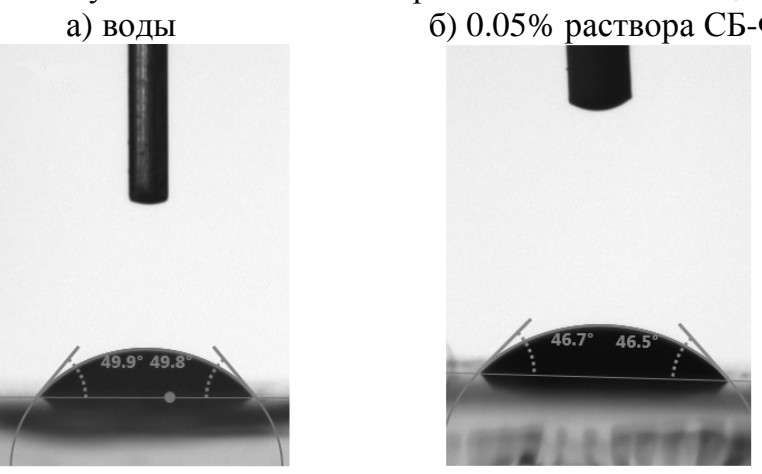

в) $0.0625 \%$ раствора $П В C$

Рис. 7. Определение краевых углов смачивания минеральной (1) и полимерной (2) поверхностей растворами: а - вода; б - СБ-ФФ; в - ПВС

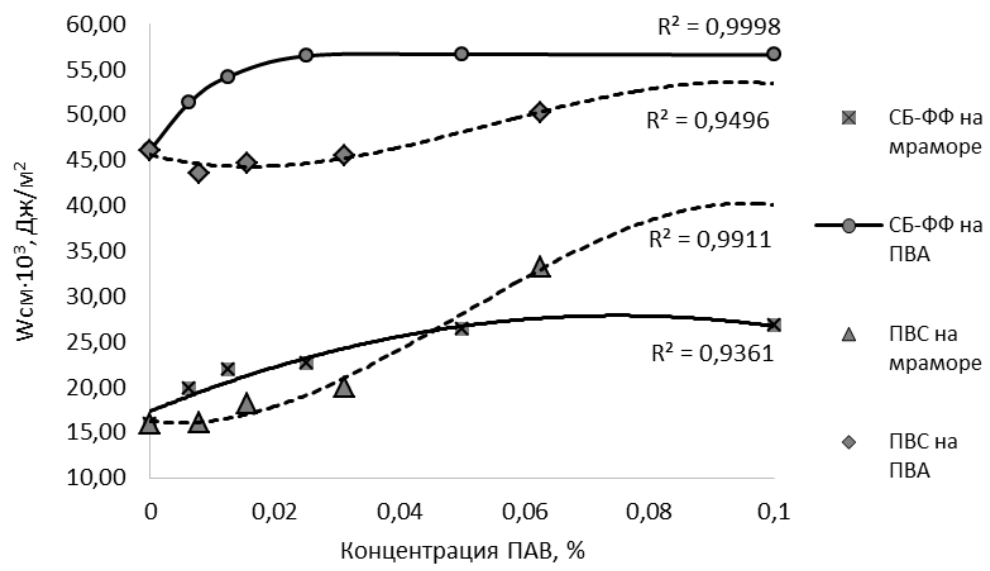

Рис. 8. Влияние концентраций поверхностно-активных веществ на работу смачивания на поверхностях мрамора $\left(\mathrm{CaCO}_{3}\right)$ и полимера (ПВА)

Таблица 2. Характеристики поверхности мрамора и поливинилацетата

\begin{tabular}{|c|c|c|c|}
\hline Вид поверхности & $\begin{array}{c}\text { Свободная энергия } \\
\text { поверхности (СЭП), } \\
\text { мН/м }\end{array}$ & Рассеивание, мН/м & Полярность, мН/м \\
\hline Минеральная $\left(\mathrm{CaCO}_{3}\right)$ & $37.73 \pm 1.77$ & $31.04 \pm 0.94$ & $6,69 \pm 0.83$ \\
\hline Полимерная (ПВА) & $60.46 \pm 1.16$ & $43.81 \pm 0.14$ & $16.66 \pm 1.02$ \\
\hline
\end{tabular}

Используя программное обеспечение ADVANCED прибора KRUSS Easy Drop DSA-30, была рассчитана свободная энергия поверхности мрамора и пленки ПВА, полученные результаты представлены в табл.2. Представленные значения СЭП исследуемых минеральной и полимерной поверхностей показывают различие в поверхностной энергии мрамора и поливинилацетата почти в два раза. Это объясняет 
агрегативную неустойчивость полимерных дисперсий и необходимость введения стабилизатора.

\section{Заключение}

Проведенные исследования доказали, что при создании перспективных полимерцементных систем для аддитивных технологий происходит коагуляция частиц поливинилацетатцементной системы в результате десорбции стабилизатора ПВС с полимерных частиц ПВА. Причиной десорбции является разбавление дисперсии водой, это имеет место при малых П/Ц и большом водосодержании полимерцементных смесей. При этом относительно небольшое количество полимерной дисперсии смешивается с большим количеством воды затворения, в результате часть стабилизирующего ПАВ с поверхности частиц поливинилацетата переходит в воду, т. е. наблюдается смещение адсорбционного равновесия в результате увеличения содержания ПВС в дисперсионной среде и десорбции с границ полимер-раствор. Другой причиной десорбции стабилизатора является добавлении к дисперсии порошкообразных материалов с развитой поверхностью - цемента. Повысить агрегативную устойчивость поливинилацетатцементных смесей позволяет введение суперпластификатора на основе флороглюцинфурфурольных олигомеров. При этом наблюдается увеличение десорбции ПВС с поверхности полимера в результате конкурентной адсорбции молекул в связи с тем, что флороглюцинфурфурольные олигомеры обладают бо́льшей поверхностной активностью на границе «поливинилацетат - дисперсионная среда полимерцементной системы», чем молекулы поливинилового спирта.

Статья подготовлена в рамках работы по заданию Министерства образования и науки России 9.11523.2018/11.12 «Разработка и исследование технологического модуля для производства высококониентрированных микро-фибронаполнителей строительных

3D-технологий» и программы развития опорного университета на базе БГТУ

им. В.Г. Шухова при разработке инновачионных материалов и композитов для аддитивных технологий (№ A-54/17 от 27 апреля 2017 г).

\section{Список литературы}

1.Ватин Н.И., Чумадова Л.И, Гончаров И.С., Зыкова В.В. и др. // Строительство уникальных зданий и сооружений. 2017. № 1 (52). C. 27-46.

2.Xi-Qiang L., Jing-Fang L., Tao Z., Liang H. et al. Патент CN, № 104310918A, 2015.

3.Tianrong Y., Qiaoling L. Патент CN, № 104891891A, 2015.

4.Ефремов И.Ф. // Успехи химии. 1982. Т. 51. вып. 2. С. 285-310.

5.Poluektova V.A., Shapovalov N.A., Evtushenko E.I. // International Journal of Pharmacy \& Technology. 2016. Vol. 8. No4. pp. 2493024937.

6.Попов К.Н. Полимерные и полимериементные бетоны, растворы и мастики. М. Высш. Школа. 1987. 72 с.
7.Шапкин Н.П., Майоров В.И., Леонтьев Л.Б., Шкуратов А.Л. и др. // Коллоидный журнал. 2014. Т. 76. №6. С.798-804.

8.Мироненко Н.В., Смусева С.О., Селеменев В.Ф., Бородкина Т.А. // Сорбичионые и хроматографические проиессы. 2017. Т. 17. № 4. C.557-563.

9.Нуштаева А.В., Вилкова Н.Г., Мишина С.И. // Коллоидный журнал. 2014. Т. 76. № 6. C.769-776.

10.Полуэктова В.А., Долгополова Е.В. // Международная научно-техническая конференция молодых ученых БГТУ им. В.Г. Шухова. 1-20 мая 2017. Белгород. 2017. С. 17581762.

11.Полуэктова В.А., Слюсарь А.А., Шаповалов Н.А. Суперпластификатор на основе флороглючинфурфурольных олигомеров для 
водных минеральных суспензий. Белгород: изд-во БГТУ. 2002. 108 с.

\section{References}

1.Vatin N.I., Chumadova L.I, Goncharov I.S., Zykova V.V. et al., Construction of Unique Buildings and Structures, 2017, Vol. 1, No. 52, pp. 27-46.

2.Xi-Qiang L., Jing-Fang L., Tao Z., Liang H. et al, Patent CN, no. 104310918A, 2015.

3.Tianrong Y., Qiaoling L. Patent $C N$, No 104891891A, 2015.

4.Efremov I.F., Uspekhi himii, 1982, Vol. 51, No 2, pp. 285-310.

5.Poluektova V.A., Shapovalov N.A., Evtushenko E.I., International Journal of Pharmacy \& Technology, 2016, Vol. 8, No 4, pp. 2493024937.

6.Popov K.N. Polymer, polymer cement concretes, solutions and mastics. M., High School, 1987, $72 \mathrm{p}$

7.Shapkin N.P., Majorov V.I., Leont'ev L.B., Shkuratov A.L. e al., Colloid Journal, 2014, Vol. 76, No 6, pp.798-804.

Полуэктова Валентина Анатольевна - доцент кафедры теоретической и прикладной химии, к.т.н., Белгородский государственный технологический университет им. В.Г. Шухова, Белгород

Шаповалов Николай Афанасьевич - профессор кафедры теоретической и прикладной химии, д.т.н., Белгородский государственный технологический университет им. В.Г. Шухова, Белгород

Кожанова Елизавета Петровна - студент кафедры теоретической и прикладной химии, Белгородский государственный технологический университет им. В.Г. Шухова, Белгород
12.Полуэктова В.А., Кожанова Е.П., Кудина А.Е. // Вестник БГТУ им. В.Г. Шухова. 2017. № 10. C.116-122.

8.Mironenko N.V., Smuseva S.O., Selemenev V.F., Borodkina T.A., Sorbtsionnye i khromatograficheskie protcessy, 2017, Vol. 17, No 4. pp. 557-563.

9.Nushtaeva A.V., Vilkova N.G., Mishina S.I., Colloid Journal, 2014, Vol. 76, No 6, pp.769776.

10.Poluektova V.A., Dolgopolova E.V. Mezhdunarodnaya nauchno-tekhnicheskaya konferentsiya molodykh uchenykh BGTU named after V.G. Shukhov, 1-20 may 2017, Belgorod, 2017, pp. 1758-1762.

11.Poluektova V.A., Slyusar A.A., Shapovalov N.A. Superplastifikator na osnove floroglyucinfurfurol'nyh oligomerov dlya vodnyh mineral'nyh suspenzij. Belgorod, BGTU, 2002, 108 p. 12.Poluektova V.A., Kozhanova E.P., Kudina A.E., Bulletin of BSTU named after V.G. Shukhov, 2017, No 10, pp. 116-122.

Poluektova Valentina A. - Ph.D. (technical), associate prof., department of pure and applied chemistry, Belgorod State Technological University named after V.G. Shukhov, Belgorod, e-mail: val.po@bk.ru

Shapovalov Nickolai A. - prof., grand Ph.D (technical), department of pure and applied chemistry, Belgorod State Technological University named after V.G. Shukhov, Belgorod, e-mail: rector@intbel.ru

Kozhanova Elizaveta P. - student, department of pure and applied chemistry, Belgorod State Technological University named after V.G. Shukhov, Belgorod, e-mail: elizzinchenko@mail.ru 